\title{
Contemporary Counselling Strategies for Persons with Disabilities
}

\author{
Melem Linda Fangwi Ph.D* \\ Department of Educational Psychology / Special Education Faculty of Education, University of Buea \\ *Corresponding Author: Melem Linda Fangwi Ph.D, Department of Educational Psychology / Special \\ Education Faculty of Education, University of Buea
}

\begin{abstract}
Persons with disabilities comprise a diverse and complex group requiring a wide range of services according to their individual needs. Counseling with children and adolescents with disabilities must be coordinated with educational services, medical and remedial specialists, family members, and the students themselves. Exceptional children and adolescents receive maximal benefits when comprehensive counseling services are offer in combination with a variety of other support services in the most normalized environment possible. This paper seeks to discuss specific counseling strategies for three categories of disabilities: specific learning disabilities, intellectual disabilities and Attention Deficit Hyperactivity disorders.
\end{abstract}

Key words: Contemporary, Counselling strategies, Disabilities

\section{INTRODUCTION}

We are all different and this is what makes us unique and interesting human beings. Some differences are obvious, such as our height, the color of our hair, or the size of our nose. Other features are not so readily discernible, such as our reading ability or our mental capabilities. Although most people would like to be thought of as "normal", for millions of children and young people, this is not possible. They have been identified and labeled by schools, social service agencies, and other organizations as exceptional, thus requiring special educational services. Children with exceptionalities are an extremely heterogeneous group of diverse learners, each with unique learning strengths and needs and most often misunderstood and frequently less served by the counseling profession (Gargiulo and Bouck, 2018).

All counselors have a professional and ethical responsibility to facilitate conditions that promote the full potential for all individuals, including exceptional groups. It imperative that all counselors who work with children and adolescents be knowledgeable about the identification of and services for those with exceptionalities. As knowledge and experience are obtained for this population, counselors can serve children and their families more fully as intended by legal and professional guidelines (Shari and Spagna, 2004).

Most counselors will encounter in their practice children and adolescents with exceptionalities. This inclusive term generally refers to individuals who differ from societal or community standards of normalcy. The concept of normalcy, which forms an important part of our definition of exceptionality, depends on the reference group (society, peers, family)as well as the specific circumstances as exceptionality is always relative to the social or cultural context in which it exists. Normalcy is a relative concept that is interpreted or judged by others according to their values, attitudes, and perceptions. Characteristics or behaviors that might be viewed as atypical or abnormal by a school counsellor might be considered fairly typical by a group of high school students. These variables, along with other factors such as the culture's interpretation of a person's actions, all help to shape our understanding of what it is to be normal (Gargiulo and Bouck, 2018).

According to WHO (2011) about $15 \%$ of the world's population lives with some form of disability, of whom 2-4\% experience significant difficulties in functioning. Throughout Africa, less than $10 \%$ of children with a disability are in primary education. In some countries only $13 \%$ receive any form of education. Persons with disabilities, on average as a group, are more likely to experience adverse educational as well as socioeconomic outcomes than persons without disabilities. This calls for 
desperate measures to be taken on the part of counsellors to ensure that those children with exceptionalities in schools are given equal chances to reduce and end their misery.

Despite the number of children and adolescents with disabilities, counseling professionals historically have had limited contact with this population for a variety of reasons. Some counselors lack confidence and training to serve these groups. Some are uncomfortable around people with disabilities. Others have incorrect information about or prejudices toward those with exceptional needs. In addition, because services to children and adolescents with disabilities are most often delivered by special education personnel, counselors may believe that their skills are not needed for these groups. Most counselors, however, do have many of the skills needed to work with these children and their families, such as communication strategies, a background in human development, and experience with an array of therapeutic techniques (Shari and Spagna 2004).

Counselors can prepare themselves to serve exceptional groups in several ways. As a first step, they must clarify their feelings and attitudes about working with children and adolescents who have disabilities. Pity, low expectations, repulsion to physical abnormalities, misinformation, and other biases can preclude effective counseling. Correct information and direct experience can facilitate accurate awareness and acceptance of these groups. In addition, counselors must obtain knowledge and training for working with specific groups with exceptional needs. They can obtain this knowledge through in-service training, counseling workshops, consultation, supervision, current therapeutic literature, and community resources Echevarria, (2002). This article presents a discussion of characteristics of children with various exceptionalities, as well as a range of counseling approaches that have proven beneficial for specific groups of children and youth with these conditions.

Exceptionality is an inclusive term which refers to individuals who differ from societal or community standards of normalcy. These differences may be due to significant physical, sensory, cognitive, or behavioral characteristics. Students identified as exceptional may require a special education and/or related services. Many of these students are categorized according to specific disability categories, with category being nothing else than people sharing a common characteristic. According to Public Law (PL) 108- 446 (the Individuals with Disabilities Education Improvement Act of 2004) identifies the following thirteen categories of disability: Autism, Deaf-blindness, Developmental delay, Emotional disturbance, Hearing impairments including deafness, Intellectual disability, Multiple disabilities, Orthopedic impairments, Other health impairments, Specific learning disabilities, Speech or language impairments, Traumatic brain injury, Visual impairments including blindness. For the purpose of this paper the following categories of developmental disabilities will be handled those having specific learning disabilities, mild mental retardation and Attention Deficit Hyperactivity Disorders. For each stratification the following will be addressed brief explanation of the concept, its characteristics, causes and the counseling therapy to be used (Gargiulo and Bouck, 2018, Shari and Spagna, 2004).

\section{CounSELling ChILdREN WiTh SPECIFIC LEARNing DiSABILITIES}

According to the Texas Council for Developmental Disabilities (2013), children and adolescents identified as having specific learning disabilities usually have a disorder in one or more of the basic psychological processes involved in understanding or using spoken or written language manifesting in an imperfect ability to listen, think, read, write, spell, and/or to perform mathematical calculations. In direct comparison to students with mild mental retardation, who have global deficits in the areas of memory and attention, individuals with specific learning disabilities have difficulties in an encapsulated area or areas of cognitive functioning which are referred to as psychological processing deficits these include deficits in perception, attention, memory, meta cognition, and organization. These deficits cause academic difficulties and result in achievement significantly below expectations given average intellectual capacity.

The world incidence of specific learning disabilities has been reported as follows among school age children ( $6-11$ years) is $1.8 \%$, while adolescents from 12 to 17 years is $2.6 \%$. Adults from 18 to 24 years the prevalence is $2.7 \%$, also adults $18-65$ years, male prevalence is $2 \%$ while female is $1.4 \%$, while the prevalence of learning disability among males above 65 years of age is $0.8 \%$ that of female is $0.7 \%$ (USA Centre for Learning Disability, 2014)

Students with learning disabilities are very heterogeneous, meaning that no two students possess the identical profile of strengths and weaknesses. One student may have a deficit in just one area while 
another may exhibit deficits in numerous areas however they are eligible for special education and related services only if they exhibit average intellectual functioning and if they exhibit the following characteristics: academic problems, disorders of attention, poor motor abilities, psychological process deficits and information-processing problems, lack of cognitive strategies needed for efficient learning, oral language difficulties, reading difficulties, written language problems, mathematical disorders, social skill deficits. It is worth noting that not all students will exhibit these characteristics, and many pupils who demonstrate these same behaviors are successful in the classroom. For students with a learning disability, it is the quantity, intensity, and duration of these behaviors that lead to problems in school and elsewhere. It should also be noted that boys are four times more likely to be labeled with a learning disability than girls. The reason for this has not yet been determined by researchers (Texas Council for Developmental Disabilities, 2013).

According to Turnbull, Turnbull, \& Wehmeyer, (2007), students with specific learning disabilities, similar to those with mild mental retardation, have low self-esteem and generally a poorly defined self-concept however their Adaptive functioning is relatively intact. They may have absolutely no deficits in perceptual-motor functioning. Except in cases where these skills are affected such as in dysgraphia, where the gross and fine-motor skills may be so involved that even beginning handwriting skills might be affected.

In the area of cognitive, processes children and adolescents with specific learning disabilities may experience any of a multitude of difficulties perception that is abilities to recognize, compare, and discriminate information, attention which inability to focus on information and this inhibit the ability to perform tasks at the appropriate achievement level. They may also have problems with working memory which affects their ability to store new information and to retrieve previously processed information from long-term memory. They may also have deficits in meta-cognition which is the ability to monitor and evaluate performance and also in organization which is the underlying thread of all these cognitive processes. Students with specific learning disabilities may have difficulties organizing their thought processes, their class work, and their environment. Because of the effect on cognitive processes, students with learning disabilities may have difficulty in a variety of academic areas as well as social and emotional development. While a student with a learning disability may have difficulties in all academic areas, major problems are more often found in reading, language arts, and mathematics Gargiulo, (2006).

In the area of social and emotional development for learners with specific learning disabilities it is important to realize that the characteristics that interfere with a student's acquisition of reading or writing skills can also interfere with his or her ability to acquire or interpret social behaviors. For example, individuals may have difficulties correctly interpreting social situations and reading social cues, and they may act impulsively without identifying the consequences of their behavior or recognizing the feelings and concerns of others (UNESCO (2018).

Learning disability is identified when there is a severe discrepancy between intellectual ability and achievement in one or more of the following areas: Oral Expression, Listening Comprehension, Written Expression, Basic Reading Skills, Reading Comprehension, Mathematical Calculation, and Mathematical Reasoning. The discrepancy must not be due to any environmental, cultural, or economic disadvantages and must not be correctable through other regular or categorical services within the regular instructional program. In simpler terms, children with learning disabilities exhibit a statistically significant gap, between their intelligence (ability) and at least one area of their academic testing (achievement). In screening for specific learning disabilities cultural sensitivity should be considered and referring students because a number of racial/ethnic subgroups have been misidentified for specific learning disabilities because of language differences, cultural mismatches in educational methodology, learning difficulties related to poverty, and teachers-versus-students cultural differences in behavioral expectations (Center on Educational Policy, 2002).

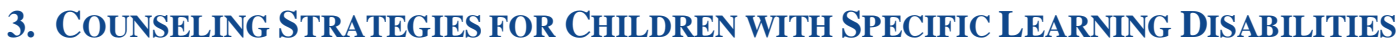

Children and adolescents with specific learning disabilities need remedial services that target specific areas of functioning. If special attention is paid to the psychological needs of pupils and students with learning disabilities, they have a much greater potential to finish school successfully. Counselors can increase that likelihood by developing long- term therapeutic relationships in which they help students maneuver through the system, acknowledging their limitations and celebrating their 
triumphs. Because most of the difficulties these children and adolescents experience are in academic areas, it is important to include teachers as team members when planning services for this group. International laws mandate inclusion in the general education classroom of children and adolescents with specific learning disabilities to the fullest extent possible. Therefore, counselors need to have contact with general education teachers and the resource specialists who provide specialized services to students with learning disabilities both inside and outside of the classroom (UNESCO (2018).

Counselors can consult with teachers about specific techniques (for example: teaching the sequentialstep approach to math problems, using repetition, teaching outlining techniques, and instructing students in the use of memory aids). Classroom modifications can be made (such as administering oral tests, using computers, audio taping lectures, reducing assignments, and allowing extended time to complete work).Motivational approaches (for instance, employing internal and external reenforcers, token economies, and contracts for adolescents) that fit each student's special needs (Westman, 1990).

Social adjustment might be an additional area of need for students with specific learning disabilities, either because of weaknesses in social perception or of being viewed as different as a result of academic difficulties. Counselors can help teachers to be role models for the rest of the class in promoting social success for students with learning disabilities and can help them facilitate supportive peer activities such as peer pairing, cooperative work groups, and classroom social skills programs (Tarver Behring et al., 1998). Counselors, can work directly with children to help raise their low selfesteem and with adolescents about their identity issues and long-term career planning, in individual and group counseling settings using various therapeutic approaches such as those stipulated by Sicoli (2006) discussed below:

Child psychotherapy: Psychodynamic therapy is a long-term therapeutic approach based on the principles and theories of psychoanalysis. The counselor works closely with the child with learning disabilities to explore repressed emotions and desires that affect their current thoughts, attitudes, behaviors, and relationships with others. As therapy progresses, the individual with learning disabilities learn to better identify and resolve problems through a new lens of understanding, and develop or improve their interpersonal relationships.

Child cognitive behavioral therapy (CBT) or talk therapy: Cognitive behavioral therapy or CBT, is a practical approach that helps the individual with learning disabilities change his or her thoughts, attitudes, beliefs, and behaviors to solve their individual problems. It is typically short-term, goaloriented, and is used to treat wide-ranging concerns in such persons.

Solution-focused therapy (SFT): this is an approach that empowers learners with specific learning disabilities to own their abilities in solving life's problems than focusing on how a problem was derived. SFT practitioners focus on goal-oriented questioning to assist the learner with specific learning disability in moving into a future-oriented direction.

Sensory integration therapy: Sensory integration is a term that has been used to describe processes in the brain that allow an individual with specific learning disability to take information he or she receives from his/her five senses, organize it, and respond appropriately. These children are exposed to sensory stimulation in a structured, repetitive way with the aim that over time, their brain will adapt and allow them to process and react to sensations more efficiently. The principle is that through repetition, the child's nervous system will respond in a more "organized" way to sensory stimuli.

Finally, counselors can offer Family therapy: where support given to parents in relation to specific difficulties and demands in the home, tutorial services to reduce parents' stress surrounding schoolwork demands; assistance in developing schedules to help parent who are frustrated because of their children's lack of organization; and referral of children to social organizations to address parents' concerns about their children's low self-esteem, social status, and long-term educational and career adjustment (Westman, 1990). The most valuable effect of family therapy is its ability to reinforce and strengthen family bonds. Family therapy can draw the family closer together and so that family members can recognize it as a strong and healthy body that is able to effectively problem solve for all members of the family unit.

Counselors who are less skilled in these interventions can team with the resource specialist to offer these services to the general education teachers. The partnership between special education and 
general education teachers is necessary for successful full inclusion, but it often does not happen without an advocate scheduling differences, and the differing roles of school personnel (Eichinger \& Woltman, 1993).

\section{Counselling Children with Mental Retardation (InTEllectual Disabilities)}

Mental retardation is defined as a category of disability with limited operative abilities in various dimensions of human functioning such as intellectual abilities, adaptive behavior, health, participation, and context. Schalock (2016) explains that human functioning is essentially viewed as "an umbrella term for all life activities and encompasses body structures and functions, personal activities, and participation, which in turn are influenced by one's health and environmental or contextual factors". This view is found acceptable as it is linked to personalized systems of supports for that individual. It is viewed as a state of functioning rather than an inherent trait.

The term mental retardation, however, is replaced by the more contemporary label intellectual disability because the term is less pejorative while also reflecting a social-ecological understanding of disability. The incidence of mild mental retardation according to data from the U.S. Department of Education (2015), approximately 415,200 children between the ages of 6 and 21 are identified and the cause ranges from organic factors, such as Down syndrome, to environmental factors, such as fetal alcohol syndrome, malnutrition, and several known maternal infections such as rubella(Gargiulo and Bouck, 2018).

The constructs of intelligence and adaptive behavior play key roles in our understanding of the concept of intellectual disability. Intelligence is perhaps best thought of as a construct or theoretical abstraction; it is not a visible entity but rather a human trait whose existence is inferred based on a person's performance on certain types of cognitive tasks. As a direct result of their sub average cognitive functioning, these children and adolescents generally learn at a slower pace than their peers without disabilities (Gargiulo and Metcalf, 2013). They also avoid attempting new tasks and use inefficient learning strategies when faced with new tasks.

In addition to having sub average intellectual functioning, these children and adolescents must be assessed as having below-average adaptive behaviors. Adaptive behavior is seen as "the degree to which, and the efficiency with which, the individual meets the standards of maturation, learning, personal independence, and/or social responsibility that are expected for his or her age level and cultural group that is "the collection of conceptual, social, and practical skills that have been learned by people in order to function in their everyday society". Stated another way, it is how well a person copes with the everyday demands and requirements of his or her environment. The idea of context is important for understanding the concept of adaptive behavior. Because behavior is strongly influenced by cultural factors, age and situation appropriateness must always be considered within the setting in which it occurs. For example, a teenage girl who uses her fingers while eating might be viewed as exhibiting inappropriate behavior; however, this behavior is maladaptive only when considered within the context of Western cultures (Gargiulo and Bouck, 2018).Some poor adaptive behaviors found in students with mild mental retardation are poor self-help skills, low tolerance, low frustration and fatigue levels, and moral judgment commensurate with cognitive functioning.

Generally speaking, students with mild mental retardation are delayed in terms of social and emotional functioning. They usually exhibit lower levels of self-esteem and a more unfavorable selfconcept than their peers without mental retardation. Because of their negative view of themselves, adolescents with mild mental retardation are overly susceptible to negative peer influences. Consequently, they might agree to experiment with foreign substances such as narcotics or to participate in gang-related activities in an attempt to gain peer acceptance (Landreth, 2012).

Perceptual-motor and language functioning also are significantly delayed in children and adolescents with mild mental retardation. This below-average functioning particularly affects their ability to participate fully in physical education activities and negatively curtails their ability to communicate socially and interact with students without mild or moderate mental retardation. Most children with mental retardation manifest some specific learning characteristics such as inability to attend to critical or relevant features of a task, diminished attention span, difficulty ignoring distracting stimuli. They exhibit deficits in memory correlated with severity of intellectual disability, limitations in ability to selectively process and store information, inefficient rehearsal strategies, difficulty with short-term memory is common recalling directions in sequence presented seconds earlier, long-term retrieval 
(recalling a telephone number) is similar tothat of peers without intellectual disability, history of and a generalized expectancy for failure, learned helplessness, effort is unrewarded; failure is inevitable, exhibit external locus of control belief that outcomes of behavior are the result of circumstances (fate, chance) beyond personal control rather than own efforts, evidence outer-directedness, a loss of confidence and a distrust of own abilities (Glanzman \& Sell, 2013).

They are reliant on others for cues and guidance, they have difficulty applying knowledge or skill to new tasks, situations, or settings, problem in using previous experience in novel situations, teachers must explicitly plan for generalization; typically it does not automatically occur, follow same sequence of language acquisition as typical individuals, albeit at a slower pace. They exhibit a strong correlation between intellectual ability and language development the higher the IQ, the less pervasive the language difficulty, speech disorders (articulation errors, stuttering) more common than in peers without intellectual disability. Their vocabulary is often limited, grammatical structure and sentence complexity are often impaired, generally exhibit difficulties in all academic areas with reading being the weakest, problem solving difficulties in arithmetic, rejection by peers and classmates is common poorinter personal skills, frequently exhibit socially inappropriate or immature behavior difficulty establishing and maintaining friendships, diminished self-esteem coupled with low self-concept (Gargiulo and Metcalf, 2013).

From the analysis above it is clear that the is need for every learner to be screened, referred, and assessed with the assessment instrument being culturally sensitive and fair manner for identification and diagnosis of intellectual disability as it is the only way the right counsel will be given them, (American Youth Policy Forum and the Center on Educational Policy, 2002).

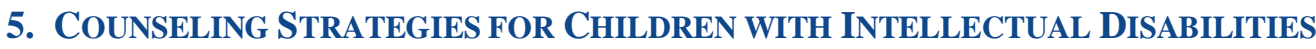

Lemay, Herbert, Dewey, and Innes (2003) hold that because they experience developmental delays in most areas of functioning, children and adolescents with mild mental retardation require multiple services. Counselors can help to coordinate school, home, and community services for all areas of need. They further state that in the school setting, children and adolescents with mild and moderate mental retardation will benefit in educational and social areas alike by being fully included in the general educational. Counselors, therefore, often work with parents, special educators, and teachers to advocate for appropriate educational modifications and resources in the general education classroom. They can help teachers to promote social adjustment for these students by providing guidance in incorporating peer modeling, self-reliance, age-appropriate social behavior, and friendship-making skills into classroom activities.

They can promote tolerance of differences in peers without disabilities through social skills programs, integrated counseling groups, and classroom modeling and discussion. Further, they can teach behavioral modification, token economy, and contingency contracting strategies to teachers and parents to assist them in helping the $\cdot$ students develop appropriate academic, social, and self-help behaviors (Tarver Behring, Spagna, \& Sullivan 1998).

Although the value of counseling with this group is controversial because of the students' cognitive limitations, it seems reasonable that counselors can offer individual and group counseling focusing on self-esteem, self-expression, and behavioral rehearsal, which are all typical areas of need. Counselors can help parents understand and encourage their child's or adolescent's abilities and help the parents cope with the stresses of parenting a disabled child. For adolescents, special attention should be given to their developing independent living skills and to educational and vocational planning (Lemay, Herbert, Dewey, and Innes, 2003).

Play therapy: Play therapy is an emerging tool for therapists forging significant headway in the treatment of children with intellectual disabilities. The child-centered play therapist is to provide a therapeutic environment in which the child feels heard, cared about, and understood (Landreth, 2012). Through an active and living relationship, children undergo a sense of mastery and control, increase self-acceptance, direction, and responsibility, and learn to rely on their internal locus of evaluation.

Children with intellectual disabilities (IDs) experience cognitive limitations and challenges in adaptive behaviors that affect their emotional and social development. Play therapy has been suggested for several decades as an intervention to help children with IDs strengthen adaptive 
behaviors and develop stronger social relationships. Play includes spontaneity, intrinsic motivation, and pleasure. Play allow them to access and explore their world. Play develops the skills which expand their physical, cognitive, and emotional abilities. It has been effectively used for teaching. While playing pupils recognize their own needs, they help in planning activity, accept guidance, and set up their own goals (Rathnakumar,2020).

Family Support: Parents are every child's most important resource, but their importance is magnified for individuals who experience a prolonged, or even persistent, period of dependency. Providing support to parents in their care giving role is a very important function of the counsellor. A family's requirement for community support depends not only on the characteristics of the child's degree of cognitive impairment, level of independence, and behavioral challenges, but on structural, functional and external characteristics of the family. There are two levels of community supports: informal and formal. Informal supports include: community organizations that provide advocacy, parent training, counseling, child care, respite, or recreational activities and social networking with other families through parent support groups and, most recently, through the Internet. Formal supports include publicly supported programs to which families are entitled. Early intervention and public schools, particularly special education programs, are entitlement programs for all children who have MR (Shari and Spagna, 2004).

\section{Counselling with Children with Attention Deficit Hyperactive Disorder (ADHD)}

Attention deficit hyperactive disorder is another category of exceptionality frequently found in our contemporary classrooms. According to the American Psychiatric Association (2013), Attention deficit hyperactivity disorders (ADHD) is "a persistent pattern of inattention and/or hyperactivityimpulsivity that interferes with functioning or development". The preceding characteristics or symptoms must be present before the age of 12 and occur in two or more settings (for example, home and school) for at least six months. Children must present at least six symptoms from either the inattention group or the hyperactivity and impulsivity criteria. Adolescents and adults (those over age 17) must evidence five criteria. The characteristics must significantly impact or impede academic, social, or occupational functioning and not result from another mental disorder. The Association's definition recognizes three subtypes of ADHD based on the individual's unique profile of symptoms: (1) predominantly inattentive type; (2) predominantly hyperactive-impulsive type; and (3) combined type. The majority of individuals with ADHD exhibit the combined type (Glanzman \& Sell, 2013).

Characteristics of persons with attention deficit hyperactivity disorder vary considerably however, there are some common features that cuts across the various categories as described by the American Psychiatric Association, Diagnostic and Statistical Manual of Mental Disorders, 5th ed. (Arlington, VA: Author, 2013). These characteristics are outlined below:

Inattention: fails to pay close attention to details, often makes careless mistakes, has difficulty sustaining attention to tasks or while playing, does not seem to listen when directly spoken to, fails to complete tasks, has difficulty organizing tasks or activities, schoolwork is often messy and disorganized, avoids or resists situations requiring sustained attention. They also lose items necessary for task completion (pencils, books, tools), are easily distracted by extraneous stimuli, are often forgetful in daily activities

Hyperactivity: fidgets or squirms, cannot sit still, demonstrates inability to remain seated for periods of time, runs or climbs excessively, has difficulty engaging in quiet leisure activities, talks excessively, is always on the go as if "driven by a motor"

Impulsivity: blurts out answers, has difficulty waiting in line or his or her turn, interrupts or intrudes on others butts into conversations or activities, acts without thinking, impatient.

The cause of ADHD is unclear. A variety of factors are associated with ADHD. Neurological variables and hereditary influences are the most likely factors. Diet and environmental toxins do not seem to significantly contribute to the presence of ADHD (Echevarria,2002).

According to Shari and Spagna (2004) children and adolescents with ADHD may or may not qualify for educational services., though they frequently have some form of academic difficulty, such as attentional or organizational problems however their achievement problems aren't always severe enough to fall into a special education category. They qualify for special education services when the 
ADHD occurs in combination with another disability, such as a specific learning disability, or when the ADHD symptoms are so severe that achievement is delayed to the extent that the child or adolescent qualifies for the special education category entitled other health impairment.

Frequently, children and adolescents with ADHD qualify for educational modifications; when they exhibit symptoms that affect learning to the extent that reasonable educational modifications are required, such as implementation of a behavioral management program; placement in a small, highly structured classroom; counseling; and the administration of medication. Classroom modifications and interventions for the child or adolescent with ADHD usually are necessary regardless of whether the child qualifies for specific educational services (Echevarria, 2002).

Children who have ADHD often are first identified at school, where their behavioral problems stand out in contrast to other children. To accurately assess for ADHD, Shari and Spagna (2004).recommended that the initial screening be followed by multiple assessment techniques such as rating scales, behavioral observations, and evaluation of academic and organizational skills in both home and school settings.

\section{COUnSEling STRATEgies FOR CHILDREN WITH ADHD}

Grönvik, (2007) holds that counseling children and adolescents with ADHD requires multiple naturalistic interventions such as behavioral modification, cognitive strategies, teacher consultation, and social skills training be implemented at home and at school before considering the use of stimulant medication, which sometimes results in side effects. Stimulant medication has been found to be especially beneficial with more severe cases of ADHD.

Behavioral Modification: this is one of the most effective treatments that counselors can use to change behavior in children with ADHD. Here counselors can teach parents and teachers positive reinforcement strategies that can increase the child's task-related attention and activity and decrease his or her disruptive behavior at home. Ideally, preferred activities rather than concrete rewards should be used as reinforcement; frequent and specific behavioral feedback should be given; and redirection and/or mild consequences should be used following inappropriate behavior (Shari and Spagna (2004).

Cognitive Behavioral Training: This approach focuses on teaching self-control through selfmonitoring strategy. The child or adolescent with ADHD uses self-reminder statements to increase awareness and control of his or her behavior when direct feedback is not available. With the selfinstruction strategy, the child learns to follow a set of self-directed instructions for completing class work. This is training is corroborated by self-reinforcement where the child uses different ways to praise/give himself or herself a reward, such as a check mark on a behavioral chart following positive behavior when external rein forcers are unavailable. This approach does not continue without the ongoing monitoring and encouragement of a counselor, parent, or teacher; therefore, it should be used in combination with other interventions and not as the only treatment strategy Echevarria, (2002).

Teacher Consultation: Counselors can consult with teachers to set up school-based interventions for children and adolescents with ADHD such as the use of behavioral techniques, for instance modeling, token economies, and home-school reward systems. Other classroom strategies may include adapting instructions to highlight the main idea, giving the students prompts to respond, teaching the students to use organizers, working with them in small groups, using visual aids, and teaching problem-solving strategies. Teachers also should offer structure, supervision, and support in classroom activities (Gargiulo and Metcalf, 2013).

Direct Counseling: Individual and group counseling can be offered to children and adolescents with ADHD to help them with issues of self-esteem and self-control. These individuals often feel low selfworth as a result of repeated negative feedback about their behavior. Among the therapeutic books available for use in counseling children with ADHD are "I Would If I Could" (Gordon, 1992) and "Putting on the Brakes" (Quinn, 1992). And games and other activities targeting ADHD behaviors are available for the counseling setting (Taylor, 1994). Group counseling can help these children and youth feel less different and more supported. Adolescent groups can promote the identification of positive role models and can help members set long-range goals as a tool for seeing themselves as having the potential for success. To help children and adolescents with ADHD maintain attention and behavior during direct counseling, structured, time-limited sessions and more directive approaches are recommended (Shari and Spagna (2004). 
Social Skills Training: Among the social problems that children and adolescents with ADHD exhibit are aggression, impulsive or intrusive conversational style, poor social problem solving, excessive talking, limited self-awareness, emotional over reactivity, and bossiness when initiating interactions. These social problems may lead to peer rejection and lower self-esteem, further complicating social adjustment. Programs that promote social adjustment can be beneficial for helping persons with ADHD. Social skills interventions for this population, however, should always be planned for specific settings, as social skills training does not automatically generalize to new social situations for them (Bender, 1997). Several general social skills instructional programs are available for counselors to use with children or adolescents with ADHD individually, in groups, or in classroom settings. One effective social skill program specifically designed for adolescents with ADHD targets methods for joining social exchanges, conversational skills, conflict resolution, and anger control. This program also involves peer models, strategies for maintaining social success, and cognitive strategies (Gargiulo and Metcalf, 2013).

Family Counseling: Families with a child or an adolescent with ADHD can benefit from counseling for difficulties linked to having a family member with this disorder. For example, the parents and ADHD child may develop codependency as the parents try to establish normalcy through solving problems, organizing work, directing impulse control, completing tasks, and guiding social situations for the child who has difficulty in these areas. In addition, the family might experience stress directly related to the child's difficulties. For instance, the child's impulsivity and over activity may keep the family in a constant state of arousal, and the child's inattention may require the parents' hypervigilance and repeated reminders. Adolescents with ADHD may lie, steal, skip school, and exhibit similar antisocial behaviors (Bender, 1997).

Through family counseling, the counselor can help all family members to acquire knowledge, understanding, and strategies for coping with the child or adolescent with ADHD without neglecting the needs of other family members. For example, parents can learn to channel their child's energies into productive activities that allow the child to attain success. Further, the counselor can help the family envision a positive future for the child by informing the parents and child of college academic and vocational options and services available for adolescents with ADHD (Shari and Spagna (2004).

Support Groups: Parents of children and adolescents with ADHD can benefit from support groups that target stress, guilt, and codependency issues. Parents find comfort when they realize that they are not alone in their feelings. The support group meetings can include lectures, demonstrations, questionand-answer sessions, or informal discussions. Counselors can help parents locate a recognized support group. Counselors can locally create, organize facilitate support groups for parents with a child or an adolescent with ADHD. These groups often are organized around specific topics. A session on prescribed medications, for example, could feature discussion by a qualified speaker or a group of experts having different points of view. Other topics might focus on how parents can help their children with ADHD in specific problem areas, such as anger control. A session on anger control might involve teaching parents to role-model appropriate anger for their child, to encourage their child to self-monitor anger, and to administer rewards to the child for the appropriate expression of anger (Taylor, 1994).

Parent education programs are available for counselors to use with parents of children with ADHD. These include the Barkley Parent Training Program (Barkley, 1990), the Patterson Parent Training Program (Newby, Fischer, \& Roman, 1991). All of these programs cover ADHD behaviors and related parenting skills; methods for consistent, positive consequences for positive behaviors; and punishment through time-out for negative behaviors which can be adapted to suit our context for effective implementation. Parents can learn to use behavioral charts with younger children. The charts list three or four target behaviors in the home and the children earn rein forcers each time the child performs a positive behavior. With adolescents, behavior can be managed through behavioral contracts negotiated with the teenager that specify ways to earn social activities and age-appropriate rewards (Shari and Spagna (2004).

\section{REFERENCES}

[1] American Youth Policy Forum and Center on Educational Policy. (2002). Twenty-five years of educating children with disabilities: The good news and the work ahead. Washington, DC: Author.

[2] American Psychiatric Association: diagnostic and statistical manual of mental disorders 
[3] Bender, W. N. (1997). Understanding ADHD: A practical guide for teachers and parents. Englewood Cliffs, NJ: Prentice-Hall.

[4] Center on Educational Policy, (2002).U.S. Department of Education

[5] Diagnostic and Statistical Manual of Mental Disorders, 5th ed.

[6] Echevarria, J. (2002, March 15). The disproportionate representation of minority students in special education: Where do we go from here? Paper presented at Oxford Round Table on Education and Human Rights at Oxford University, Oxford, England.

[7] Eichinger, J., \& Woltman, S. (1993). Integration strategies for learners with severe multiple disorders. Teaching Exceptional Children, 26, 18.

[8] Gargiulo R. M. \& Bouck,Emily C (2018) Special Education in Contemporary Times; an Introduction to Exceptionality Sixth Edition, SAGE Publications, Inc.

[9] Gargiulo, R.M. (2006). Special education in contemporary society: An introduction to exceptionality. Belmont, CA: Thomson Wadsworth.

[10] Grönvik, L. (2007a). "The fuzzy buzz word: conceptualisations of disability in disability research classics. Sociology of Health and Illness", July, Vol. 29 Issue 5, 750-766.

[11] Gross, B.H., and Hahn, H. (2004). "Developing issues in the classification of mental and physical disabilities". Journal of Disability Policy Studies, 15(3), 130-134.

[12] Gordon, M. (1992). I Would If I Could. DeWitt, NY: GCL Barkley, 1990),

[13] James A. Sebben (2001) The Role of Family Therapy in the Treatment of Children and Adolescents with Learning Disabilities. All about Learning disabilities and ADHD

[14] J.F. Lemay, A.R. Herbert, D.M. Dewey, A.M. Innes (2003). A rational approach to the child with mental retardation for the pediatrician. Pediatric Child Health;8(6):345-356.

[15] Landreth, G. L. (2012). Play therapy: The art of relationship (3rd ed.) New York: Routledge

[16] Marianne Glanzmanand Neelam Sell(2013). Children with disabilities $7^{\text {th }}$ ed Baltimore : Paul H. Brookes Pub.

[17] Mathiowetz, N. A. (2001). "Methodological issues in the measurement of persons with disabilities". In Barnartt, S.N. and Altman, B.M. (Editors.), Exploring theories and expanding methodologies: Where we are and where we need to go (Vol. 2, 125-143). (Oxford: Elsevier).

[18] M. L. Corbin Sicoli (2006)Counseling Strategies for College Students with Learning Disabilities. Journal of Reading, Writing, and Learning Disabilities International Vol 2,Issue 4, 291-293

[19] Newby, R., Fischer, M., \& Roman, M. (1991). Parent training for families of children with ADHD. School Psychology Review, 20, 252-255

[20] Quinn, P. (1992). Putting on the brakes. New York: Magination.

[21] Rathnakumar, D. (2020) "Play Therapy and Children with Intellectual Disability." Shanlax International Journal of Education, vol. 8, no. 2, pp. 35-42.

[22] Richard M. Gargiulo, Debbie Metcalf (2013).Teaching in Today's Inclusive Classrooms: A Universal Design for Learning Approach 3rd Edition Pub: Cengage Learning.

[23] Schalock, R. L. (2016)The Relation Between Intellectual Functioning and Adaptive Behavior in the Diagnosis of Intellectual Disability, Intellectual Developmental Disabilities, 54, 381-390.

[24] Sicoli Mark A. (2006). Why phonology and phonetics matter in the study of language ideologies. Guest Lecture in Graduate Seminar University of Michigan.

[25] Tarver-Behring, Shari, and Michael E. Spagna. (2004). Counseling with Exceptional Children Focus on Exceptional Children 1-12; vol 36, no 8

[26] Tarver Behring, S., Spagna, M. E., \& Sullivan, J. (1998). School counselors and full inclusion for children with special needs. Professional School Counselor, 1, 51-56.

[27] Taylor, J. F. (1994). Helping your hyperactive/attention deficit child. New York: Prima.

[28] Texas Council for Developmental Disabilities (2013), Project IDEAL in Action.

[29] Turnbull, A., Turnbull, R. \& Wehmeyer, M. L. (2007). Exceptional lives: Special education in today's schools. Upper Saddle River, NJ: Pearson Merrill Prentice Hall.

[30] U.S.A. National Centre for Learning Disability (2014) the state of learning Disabilities. http//www. ncid.org/wp. content/ uploads/2014/11/2014 state of LD.

[31] UNESCO (2018) Education and Disability: Analysis of Data from 49 Countries. UNESCO Institute for Statistics (UIS), Education and Disability.

[32] Westman, J. C. (1990). Handbook of learning disabilities: A multisystem approach. Boston: Allyn \& Bacon. 
[33] WHO (2011) World Report on Disability. WHO Library Cataloguing-in-Publication Data

Citation: Melem Linda Fangwi Ph.D. "Contemporary Counselling Strategies for Persons with Disabilities" International Journal of Humanities Social Sciences and Education (IJHSSE), vol 7, no. 9, 2020, pp. 58-68. doi: https://doi.org/10.20431/2349-0381.0709005.

Copyright: (C) 2020 Authors. This is an open-access article distributed under the terms of the Creative Commons Attribution License, which permits unrestricted use, distribution, and reproduction in any medium, provided the original author and source are credited. 